\title{
Grating Cycles per Centimeter
}

National Cancer Institute

\section{Source}

National Cancer Institute. Grating Cycles per Centimeter. NCI Thesaurus. Code C114242.

A unit of measure for the number of repeating vertical or horizontal bars per unit of

leng th equal to one centimeter on a visual acuity testing card. 